\title{
Urdimento
}

Revista de Estudos em Artes Cênicas

E-ISSN: 2358.6958

\section{Considerações sobre o conceito de site-specific no Teatro Brasileiro}

José Jackson Silva

Walter Lima Torres Neto

\section{Para citar este artigo:}

SILVA, José Jackson; TORRES NETO, Walter Lima. Considerações sobre o conceito de site-specific no Teatro Brasileiro. Urdimento, Florianópolis, v. 2, n. 38, ago./set. 2020.

DOI: http:/dx.doi.org/10.5965/14145731023820200025

Este artigo passou pelo Plagiarism Detection Software | iThenticate 
Considerações sobre o conceito de site-specific no Teatro Brasileiro

José Jackson Silva ${ }^{1}$

Walter Lima Torres Neto²

\begin{abstract}
Resumo
Neste artigo visitamos um conjunto de definições sobre o uso e emprego do termo site-specific em montagens teatrais brasileiras contemporâneas. Para tanto, partimos de diversas definições iniciando pela alusão que as artes visuais fazem à expressão. Procuramos problematizar os aspectos do processo criativo considerando a palavra de agentes criativos, quando se expressam nos programas de seus espetáculos ou em entrevistas, a expressão da crítica especializada e os textos acadêmicos e universitários que procuram abordar os mais diferentes aspectos que envolvem o termo e a noção que o encerra.
\end{abstract}

Palavras-chave: Site-specific. Encenação. "Teatro Alternativo". Dramaturgia do espaço.

\title{
Considerations on the site-specific concept in Brazilian Theatre
}

\begin{abstract}
In this article we visit a set of definitions about the use of the term sitespecific in contemporary Brazilian theater productions. For this purpose, we start from various definitions starting with the allusion that the visual arts make to expression. We seek to problematize the aspects of the creative process considering the word of creative agents, when expressing themselves in the programs of their shows or in interviews, the expression of specialized criticism and academic and university texts that seek to address the most different aspects involving the term and notion that encloses it.
\end{abstract}

Keywords: Site-specific. Staging. Alternative Theater. Space Playwriting.

${ }^{1}$ Prof. substituto do Centro de Artes da Universidade Regional do Cariri (CA-URCA). Doutorando do Programa de Pós-graduação em Artes Cênicas da Universidade Federal do Rio Grande do Sul (UFRGS). jacksontea@gmail.com

2 Prof. Dr. Estudos Teatrais nos Cursos de Graduação e Pós-graduação em Letras na Universidade Federal do Paraná (UFPR) e no Programa de Pós-Graduação em Artes Cênicas (PPGAC) da Universidade Federal do Rio Grande do Sul (UFRGS). gualter20@gmail.com 


\begin{abstract}
Não existe uma forma de teatro que seja a única realmente artística. Vocês podem fazer os bons atores representarem hoje num celeiro ou num teatro e amanhã num botequim.
\end{abstract}

(Max Reinhardt)

A ideia expressa por Max Reinhardt, em nossa opinião, pode ser entendida como uma consciência sobre o espaço teatral que extrapola as convenções da caixa cênica ao tomar espaços ordinários, não teatrais, em espaços cênicos. Essa operação lança a linguagem teatral contemporânea num campo semântico que, longe de ser reducionista, expande as fronteiras da teatralidade e das relações entre atores e público. Pois, a presença do ambiente cênico no interior dessas propostas de encenação contribui para novas formas de comunicação do trabalho teatral, e, também, revela procedimentos criativos que partem de aspectos intrínsecos ao próprio espaço.

Em algumas encenações onde há esse tipo de apropriação de espaços não convencionais, os artistas exploram não apenas a localização desse lugar, mas herdam o contexto que se inscreve neste espaço, relacionando-o com a linguagem da própria encenação, que é concebida a partir das especificidades deste mesmo espaço.

Para perceber o itinerário no Brasil sobre o uso do espaço não convencional - denominado "alternativo" - até nos defrontarmos com propostas de encenações em site specific, devemos lembrar o processo de adoção do palco em arena, nos anos 1950, entre nós. A experiência brasileira do palco em arena remonta a uma outra experiência, um pouco mais anterior. Nela, se constata que uma linguagem estética e uma orientação política se combinam no propósito de alcançar outro público para suas produções.

\title{
Sobre a experiência dos Estados Unidos e o Teatro de Arena
}

Entre 1935 e 1939, tem lugar nos Estados Unidos talvez o maior projeto teatral organizado pelo governo federal americano. O Federal Theatre Project foi criado 
dentro do âmbito do New Deal, em associação com a Works Progress Administration (WPA) durante o governo Roosevelt ${ }^{3}$. Sua finalidade precípua era oferecer trabalho aos profissionais do teatro (artistas e técnicos), que se viram impossibilitados de exercer suas funções devido a grande crise econômica que afetou o país, obrigou o fechamento de muitos teatros e, consequentemente, postos de trabalho. Outra finalidade importante foi a possibilidade de, com este mesmo projeto, levar teatro para um público até então pouco prestigiado por esta arte, seja por restrições econômicas e sociais ou até por preconceitos culturais.

Apesar de ser um projeto federal, o mesmo se capilarizou rapidamente por meio da associação entre o departamento central e suas diversas seções regionais, estaduais e municipais. À medida que se estendia país afora, associou outras linguagens, como teatro para infância e juventude, dança, música e até mesmo programas radiofônicos. Estima-se que as montagens do Federal Theatre Project alcançaram 30 milhões de espectadores e empregaram cerca de 10 mil trabalhadores, entre artistas e técnicos.

A forma teatral de maior difusão junto ao público urbano ou rural, entre trabalhadores, operários e camponeses, foram os Livings Newspaper. Tratava-se de uma modalidade do teatro jornal, uma forma teatral de documentário decalcada dos fatos e acontecimentos reais, que geravam debates entre a audiência e o elenco. Resumidamente, pode-se dizer que seria uma versão de formas do agitprop-theatre, fundamentada por Erwin Piscator.

Em seu repertório, encontram-se montagens emblemáticas, como One-Third of a nation (1938); The cradle will rock (1938), esta dirigida por Orson Welles; e The Swing Mikado (1938), versão com atores negros para o Mikado de Gilbert e Sullivan, produzida pela seção de Chicago. Macbeth (1936) foi outra montagem memorável do Federal Theatre Project, encenada também por Orson Welles. Tratava-se de uma transposição da peça de Shakespeare para um país imaginário nas Antilhas. A montagem ficou conhecida por Voodoo-Macbeth, e era igualmente encenada por atores negros.

3 Cf. Iná Camargo Costa, 2001, p. 99-106. 
À frente deste grande projeto esteve a autora e professora de teatro Hallie Flanagan e o dramaturgo Elmer Rice, este na direção da seção da cidade de Nova Iorque, uma das mais importantes na economia do projeto. Flanagan, em 1926, foi a primeira mulher a conseguir uma bolsa de estudos da fundação Guggenheim. Essa bolsa permitiu que ela viajasse pela Europa e pudesse entrar em contato com o trabalho de Stanislavski, Meyerhold, Piscator, Edward G. Craig, dentre outros importantes realizadores teatrais atuantes na cena europeia do entre guerras.

Com esse currículo, tendo circulado inclusive pela União Soviética e produzindo teatro-jornal, em 1938 foi convocada pelo Comité de atividades antiamericanas do senado americano para esclarecer as políticas empreendidas pelo Federal Theatre Project. Flanagan foi acusada de subversão por apoiar um ideário socialista e defender o interesse de minorias, enfatizando em seus projetos um teor excessivamente popular, progressista em relação ao repertório e ao público.

É a este projeto, orientado sobremaneira à esquerda dos interesses do capitalismo e acusado de "marxismo cultural" num período de caça às bruxas, que se associa Margo Jones. Em seu livro, Theatre-in-the-Round, fortemente inspirado na experiência do Federal Theatre Project, ela reivindica a disseminação pelos Estados Unidos, em cada cidade, de uma nova concepção de espaço cênico e de edifício teatral "alternativo" ao espaço teatral do mainstream. Orientada por sua trajetória bem-sucedida com a adoção deste tipo de espaço teatral, Margo Jones relata sua trajetória à frente do Theatre'50, na cidade de Dallas. Este foi o primeiro teatro de arena profissional dos Estados Unidos, inaugurado no verão de 1947.

Em seu livro, Jones enfatiza ainda os pontos relevantes associados a esse tipo de espaço: baixo custo no financiamento da sua construção; baixo custo de manutenção; possibilidade de ser instalado em locais pré-existentes, como universidades, associações de recreação com YMCA, centros de cultura, museus, dentre outras organizações sociais; chance de atrair jovens talentos; facilidade na adaptação de um repertório, que não necessita de grandes e custosas construções cenografias; agilidade nas turnês (circulação) para outros espetáculos montados sob a mesma configuração; descentralização em relação ao padrão de produção 
associado ao teatro realizado na Broadway; espaço estimulante para fixação de companhias amadoras e de jovens profissionais; configuração espacial a ser experimentada por novos dramaturgos.

Como se notará abaixo, a adoção do teatro em formato arena, como idealizado nos Estados Unidos, fará sua entrada na cena teatral brasileira pelo ambiente acadêmico. Será desde o ambiente formativo que esta tipologia espacial iniciará sua carreira entre nós.

\section{Sobre espaço "alternativo" e site-specific}

É sabido no Brasil que a difusão deste tipo de espaço teatral esteve a cargo da iniciativa de José Renato Pécora, um dos fundadores e diretor do Teatro de Arena de São Paulo. A defesa deste tipo de espaço foi feita, inclusive, numa comunicação apresentada por ele e seu colega Geraldo Mateus Torloni, sob orientação de Décio de Almeida Prado4 ${ }^{4}$ É notório, também, que foi a leitura do livro de Margo Jones que impulsionou o trabalho teatral do jovem José Renato.

Formado na primeira turma de Escola de Arte Dramática, José Renato decide-se pelo palco em arena ao procurar um espaço "alternativo" para iniciar sua vida profissional. Os benefícios deste tipo de espaço, elencados acima, são reforçados nesta comunicação, que defendia uma solução para falta de casas de espetáculos que, àquela altura, ainda havia em nosso país.

Fundamentalmente, de um ponto de vista geral, o espaço teatral arena reduz a distância entre espectadores e atores, e, sobretudo, democratiza o olhar do público. Esse espaço teatral em arena diverge do espaço teatral frontal ou do dito "palco italiano" porque age sobre os protocolos de hierarquia social. Ele abre a possibilidade de uma distribuição mais democrática do público em relação aos conteúdos da cena. Com isto, queremos dizer que a escolha de um espaço teatral para uma determinada montagem é naturalmente estética, mas não deixa de ter

${ }^{4}$ A comunicação, apresentada no Primeiro Congresso Brasileiro de Teatro, intitulava-se: "O Teatro de Arena como solução do problema da falta de teatros no Brasil". 
implicações políticas.

O espaço teatral do palco em arena, devido suas proporções e configurações, se apresenta a priori como um espaço não ilusionista. Este anti-ilusionismo préfabricado desde sua planta-baixa se verifica, por exemplo, na impossibilidade de se impor uma cena em perspectiva, com ponto de fuga à maneira do palco frontal.

Em relação ao jogo do ator, essa proximidade acima mencionada sugere uma outra abordagem na relação papel-ator-personagem em termos de expressão corporal e vocal. Do ponto de vista da recepção do espetáculo, o ilusionismo é subtraído pela possibilidade de o espectador A perceber, por meio do seu olhar que "vaza" a cena, o olhar do espectador B à sua frente, e vice-versa. Trata-se da imposição de uma outra convenção entre palco e plateia. Ou seja, as propriedades da configuração de um palco em arena propiciam fortemente uma estética mais afeita a uma narrativa épica do que propriamente uma narrativa dramática.

Mencionamos essa dicotomia entre uma estética épica e dramática para salientar que se a "chave estava trocada" no registro da organização da narrativa de Eles não usam Black-tie, em termos da adoção do palco em arena, nos parece o contrário 5 . Seu emprego foi acertado. Isto é, a escolha por este espaço "alternativo" nos parece atinente à matéria da peça, que apresentava pela primeira vez em cena o operário brasileiro, uma greve, uma família de proletários. Consciente ou inconscientemente, a escolha desta tipologia de palco não poderia ter sido melhor naquela altura, visto que a cena concebida desde um palco frontal italiano era inerente aos conteúdos de uma estética burguesa.

Em um segundo momento, constata-se que desde meados dos anos 1960 existia a convivência de uma série de propostas espaciais que tomaram conta das práticas teatrais. Em 1968, por exemplo, o argentino Victor Garcia encenou o texto Cemitério dos automóveis, de Fernando Arrabal, em São Paulo, em um galpão onde funcionava uma oficina mecânica cujas características foram preservadas para a encenação; já na década de 1970 o Teatro Oficina, sob direção de Zé Celso

${ }^{5}$ Cf. Iná Camargo Costa, 1996, p. 20-55. 
Martinez Corrêa, realizou diversos experimentos cênicos, nominados por ele de Te-ato, que eram realizados em lugares insólitos (fábricas, fazendas, praças, rios, etc.); lembremos também da concepção de $A$ grande viagem ao centro da terra, de Ricardo Karman e Otávio Donasci, realizada em São Paulo em 1992, no túnel abaixo do rio Pinheiros, utilizado como espaço cênico. É possível perceber, com esses rápidos exemplos, uma radicalização da concepção espacial dessas montagens em relação ao palco em arena ${ }^{6}$.

Tantas são hoje as propostas realizadas em espaços não-teatrais, quanto as estratégias criativas, oriundas da diversidade regional, social, identitária e temática colocada em prática pelos agentes criativos brasileiros nos últimos tempos. De maneira geral, grupos, companhias e coletivos, para se expressarem cenicamente, buscam no termo "teatro em espaço "alternativo" ou "espaço não convencional" uma espécie de definição geral para concatenar a obra cênica e sistematizar seus processos criativos. Algumas dessas propostas realmente utilizam o espaço como alternativa distinta da sala de teatro, enquanto outras provocam o estranhamento no espectador menos afinado com as novidades teatrais, quando se denominam como encenações em site-specific.

Estamos interessados em apreciar melhor a expansão e a dimensão desta definição - teatro site-specific - que anima as iniciativas desses agentes criativos. Nos interrogamos sobre os seus fundamentos conceituais, que inserem o teatro em um ambiente "poroso", repleto de referências culturais que emanam do real, e que se manifestam nas suas estruturas sociais. Essa porosidade, entre ficcional e real, impacta diretamente na experiência artística. Deste modo, o que está subentendido no uso dessa denominação e prática cênica? Para chegarmos a um bom termo, precisamos perceber os sentidos atribuídos ao site-specific ao longo do tempo.

Como terminologia discursiva, a arte site-specific localiza-se no fim da

${ }^{6}$ Os mesmos diretores montaram a peça Merlin (texto de Luis Alberto de Abreu) que começou num ônibus transformado em espaço cênico que levou o público - enquanto a peça aconteceu dentro do ônibus - para um aterro sanitário nas redondezas de São Paulo. O sanitário era escolhido claramente com o intuito de oferecer um lugar site-specific que juntasse aspectos da narrativa ficcional e de uma realidade complementar empírica. 
década de 1960, em decorrência de uma reação dos artistas plásticos às condições de exposição, circulação e acesso das obras. Nesta ocasião, passaram a denunciar a não neutralidade do espaço institucional e a recusa de um modelo de mercantilização da arte, como aponta Miwon Kwon (2002), ao enfatizar o engajamento dos artistas minimalistas na proposição de trabalhos fora das galerias, concretizando suas propostas no espaço comum e ordinário do cotidiano, em contraposição ao idealismo modernista. Em vista disso, "os trabalhos sitespecific, partiram do desafio epistemológico de realocar o significado interno do objeto artístico para as contingências de seu contexto." (Kwon, 2002, p. 12).

Nesta proposta, a utilização do espaço na composição do trabalho artístico muda, de uma definição de suporte em um local fixo, pré-determinado (em galerias e museus, como garantia existencial e validação enquanto trabalho artístico), para se concentrar nos limites entre o espaço interior e exterior da obra, ao assumir o ambiente como parte indivisível e amplamente influente na obra. Nesta perspectiva, de acordo com Serra (1969, p. 22) "os trabalhos tornam-se parte do lugar e reestruturam sua organização tanto conceitual quanto perceptual, pois, um trabalho site-specific não é para ser realocado. Removê-lo é destruir a obra.” (apud Kwon, 2002, 12).

Esta seria a maneira através da qual a prática site-specific viria a radicalizar a relação com o local onde o trabalho artístico é realizado, causando uma mudança de paradigma ao conectar o ambiente na experiência artística, tanto para os artistas na criação e produção das obras, quando para o público ao apreciar o trabalho.

No teatro, Richard Schechner, em o Teatro Ambientalista, nos oferece alguns rastros para entendermos o desenvolvimento desse conceito, ao defender que o espaço cênico é formado não apenas pelo lugar que abriga o espetáculo, mas pela totalidade do ambiente que circunda o evento cênico e todos os seus agentes. É, pois, um espaço expandido que inclui desde as paredes, teto e piso, passando pelo imaginário construído sobre o lugar e a relação entre atores e espectadores, e onde todos os aspectos da representação estão envolvidos ativamente. (Schechner, 1994, p. 14). 
Nesta percepção, o lugar teatral funciona como um microespaço dentro de outro espaço ainda mais complexo - a cidade - que por sua vez espelha o contexto sociopolítico/ histórico pertencente a estes espaços, que não deve ser negligenciado na encenação ambientalista, pois, em certa medida, a convenção espacial utilizada na proposta cênica se ocupará de tais referências, em diálogo com as demandas próprias de cada processo criativo.

Sendo fruto de uma evolução dos processos de composição e formulações históricas acerca do espaço cênico, o teatro ambientalista entende que, se não existe um espaço cênico igual ao outro, tampouco existe um espaço padrão para comportar uma encenação ambientalista. Sua orientação se dá no sentido de organizar o espaço cênico de modo global, multifocal, em um microcosmos relacional que permite contato e interação entre os agentes do espetáculo.

Igualmente como se deu nas artes plásticas, a correlação do lugar não-teatral vinculado ao trabalho artístico estabeleceu as bases do teatro ambientalista, que, posteriormente, incidiria na concepção de teatro site-specific.

Embora os agentes das artes cênicas tenham experimentado realizar eventos em espaços não-teatrais há séculos (haja visto o desenvolvimento do Teatro Medieval), foi somente na década de 1980, segundo Fiona Wilkie (2004), que o termo site-specific passou a ser usado em larga escala no teatro inglês e, desde então, tem sido matéria de pesquisa de vários criadores, que se detém sob esta modalidade para tentar definir suas particularidades conceituais e também metodológicas, uma vez que estão inseridos dentro do grande leque da Performance Art, que por si extrapola os limites das convenções teatrais para o uso do espaço cênico.

Nesta esfera, a encenação configura-se a partir de um lugar não-teatral, fator que de início já apresenta uma dificuldade para quem pretende aventurar-se em esboçar uma definição que possa dar conta de toda a complexidade dos espaços disponíveis para essas encenações, dado a variedade de lugares apoiados nesta modalidade teatral (espaços encontrados, espaços arranjados, espaços adaptados, espaços desmaterializados, em espaços abertos, fechados ou virtuais), 
e também pelas diferentes particularidades de cada espaço, quando apresentam características semelhantes.

Contudo, diante da tarefa de articular uma definição de teatro site-specific, Patrice Pavis, em seu dicionário, postulou:

Este termo se refere à encenação e espetáculos concebidos a partir e em função de um local encontrado na realidade (e, portanto, fora dos teatros estabelecidos). Grande parte do trabalho reside na procura de um lugar impregnado por uma forte atmosfera: barracão, fábrica desativada, parte de uma cidade, casa ou apartamento. A inserção de um texto, clássico ou moderno, neste local descoberto the confere uma nova iluminação, uma força insuspeitada e instala o público numa relação completamente diferente com o texto, o lugar e a intenção. Este novo quadro fornece uma nova situação de enunciação que, como na land art, faz-nos redescobrir a natureza e a disposição do território e dá ao espetáculo uma ambientação insólita que constitui todo seu encanto e força. (Pavis, 2007, p. 127).

Primeiramente, nessa observação de Pavis, percebemos que o termo opera em função do espaço encontrado na realidade tangível do nosso cotidiano: garagens, galpões, igrejas, fábricas desativadas, apartamentos, parques, etc., que são apropriados pelos artistas como espaço cênico para as suas criações. Com isso, descarta-se qualquer vinculação entre a prática do teatro site-specific com o monumento arquitetônico idealizado para a exposição dos trabalhos cênicos e as convenções que dele emergem (exceto quando este espaço é ressignificado para atuar sob as convenções do site-specific).

Nestes espaços se estabelece, de pronto, uma mudança de paradigma no arranjo espacial destinado ao encontro dos atores e público, uma vez que não possuem divisão entre palco e plateia (a priori), e trazem à tona a realidade do local como potência significante da encenação.

Na leitura de Pavis, a utilização desses espaços favorece, ainda, uma ambientação incomum para a peça, e oferece um meio para abrigar uma leitura excepcional de um texto dramático, que, por sua vez, desencadeia diversas relações que a peça possa vir a estabelecer com o público ao tomar a natureza do espaço como enunciado do espetáculo. 
Entretanto, vale ressaltar que, na encenação site-specific, o local selecionado como espaço cênico provavelmente não será concebido como um pano de fundo interessante e desinteressado no significado da construção do espetáculo, como as palavras de Pavis podem sugerir, nem tampouco uma ilustração/ambientação incomum para um texto dramático, uma vez que o teatro "site-specific vincula a encenação a um espaço por meio dos processos significantes que do próprio espaço emergem, sejam eles narrativos, simbólicos ou estruturais, que estarão presentes de alguma forma na constituição do espetáculo." (Wilkie, 2002, p. 14).

\section{Sobre exemplos de site-specific}

Vejamos, por exemplo, a encenação do espetáculo A Morte de Danton, realizada por Aderbal Freire em 1977, dentro de um canteiro de obras do metrô no centro do Rio de Janeiro. A dramaturgia apresenta passagens da vida de um dos lideres da Revolução Francesa, e admite, nesta encenação, o subterrâneo como potência de vida, em oposição à superfície como morte (a derrocada do projeto revolucionário/a realidade), apontando para uma dialética que afasta a significação única e primária do subterrâneo como "esconderijo", ampliando, sobretudo, o efeito teatral. (Kosovski, 2009, p. 12).

Nesta inversão topológica, a teatralidade se concretiza e o espaço cênico passa a ser preponderante na concepção da encenação, ao materializar certas questões pretendidas pelo encenador, que revela:

A cidade estava toda escavada pelo metrô e eu olhava e dizia que ali dava para fazer um espetáculo. Em algum momento eu disse que seria muito legal fazer A morte de Danton. Teve um momento que juntou [...]. Primeiro, isso talvez possa ter nascido intuitivamente, como um intuito de discutir a questão da origem da sociedade burguesa, que é o que de fato fala A morte de Danton, que vai à Revolução Francesa, com os mesmos ideais de liberdade, fraternidade e igualdade, e naquele momento o fim da sociedade burguesa no Brasil, com a ditadura militar, fazia sonhar [...] com outra transformação, de novo propondo os mesmos temas que essa civilização burguesa não tinha cumprido [...]. Eu achava que esse tema era um tema proibido e, mesmo que me deixasse, eu queria sublinhar o seu caráter de proibido e queria falar dele debaixo da terra. Era um tema subterrâneo, ele não estava na superfície. [...] tinha 
que falar dele de forma subterrâneas. (Freire Filho apud Kosovski, 2009, p. 4).

Nesse testemunho, observamos a flagrante convergência da promessa de futuro evocada pela Revolução Francesa, justaposta com a realidade brasileira de então, onde a promessa de futuro (liberdade e criação) só poderia ser reivindicada no subterrâneo, em oposição a superfície (realidade opressiva) de um país em plena ditadura.

O conceito de espaço na encenação de Aderbal Freire se associa à obra de Büchner por meio de vínculos políticos, simbólicos e materiais. Isso se dá por meio do desejo do diretor em falar sobre a liberdade num espaço de confinamento, que espelhava a atualidade política brasileira, naquele momento histórico. Isso se dava por conta da radicalidade de uma obra ser encenada no subterrâneo, junto aos alicerces da construção do metrô, no centro da cidade do Rio de Janeiro. Sem a escolha por tal locus para encenação, não seria possível concretizar a ideia da encenação.

Neste exemplo, podemos observar que a locação da encenação em espaço "alternativo", diferente daquele para o qual foi concebida, poderia destruir a obra, pois as características inerentes àquele espaço são únicas e estão imbricadas diretamente na estrutura do espetáculo, que devem ser preservadas para dar sentido ao trabalho desenvolvido naquele espaço público. Pois, como bem sublinha André Carreira (2017, p. 104):

Se estiver pensando a cidade apenas como imagem arquitetônica, se não se explora a capacidade de fazer com que os novos espaços penetrem a cena, portanto, estará se reforçando exclusivamente sua função cenográfica. A mobilidade não põe fim à originalidade, nem corrói a ideia do efêmero da cena. Essa re-fabricação que também é comum nas obras de site-specific, re-contextualiza o trabalho mais conceitual, sempre e quando se descobrem caminhos que estabeleçam novos diálogos com a cidade.

Voltando à definição de Pavis, num segundo momento ele destaca o caráter conceitual dessa criação teatral, que, no seu entendimento, se refere a uma atmosfera que ronda os espaços destinados à encenação site-specific, podendo ser entendida como os rastros impregnados pelo cotidiano no qual a encenação se desenvolve, e que será de grande valia tanto para ressignificar o texto dramático, quando para afetar a percepção do espectador. 
Ratificando este raciocínio, Nick Kaye (2000) ressalta que, ao tentarmos traçar uma definição para o teatro site-specific, devemos recorrer necessariamente à própria origem do conceito, pois ele estimula uma investigação mais ampla de como podemos entender o espaço como sendo menos fixo ou menos geográfico e mais virtual, pelas características não palpáveis dos espaços. Nas suas palavras:

Não é apenas fornecer um modelo de relacionamento de um não-espaço em espaço cênico, mas no contexto de uma definição transitória de espaço, a especificidade do espaço em si. É nesse contexto que a arte site-specific frequentemente trabalha para problematizar as oposições entre o espaço e a obra. É também nesta oposição que as abordagens das artes visuais e da arquitetura percebem o espaço, ou podem ser lidas, através do termo performance. (Kaye, 2000, p. 19). ${ }^{7}$

Neste entendimento, sugere que o espaço vinculado à prática do teatro sitespecific deva ser fundamentado a partir do entendimento das especificidades (o que ele chama de virtualidades) do espaço, que são transitórias e efêmeras, não somente a partir do perímetro geográfico (fixo e imutável) que o espaço ocupa.

Observemos essa fundamentação espelhada em outro exemplo prático: no ano de 1995, na cidade de São Paulo, o coletivo Teatro da Vertigem, sob o comando do diretor Antônio Araújo, concebeu o espetáculo O Livro de Jó, dentro do hospital Humberto I. A dramaturgia, inspirada em um dos livros da bíblia, segue a trajetória da vida de Jó, homem que teve sua fé posta à prova num joguete entre Deus e o Diabo, que, para provar a fidelidade do homem aos desígnios sagrados, the impõe privações de toda sorte: modifica sua vida, mata seus filhos, adoece seu corpo e o relega à solidão.

Ao convidar o público para apreciar tal encenação dentro do hospital, o grupo, imediatamente, lança esses convidados numa encruzilhada de referências, pois o local carrega consigo uma carga dramática densa que perpassa por lembranças e sensações ressonantes que the são inerentes: dor, medo, repulsa, nascimento,

It is not just providing a model of the relationship of a non-space in scenic space, but in the context of a transitive definition of space, the specificity of space itself [...]. It is in such contexts that site-specific art frequently works to trouble the oppositions between the site and the work. It is in this troubling of oppositions, too, that visual art and architecture's approaches to site realize or may be read through the terms of performance. (Tradução nossa) 
morte, desespero, reabilitação, confinamento, etc., que não fazem parte dos perímetros e padrões técnicos do edifício em si, mas da funcionalidade, contexto e implicações práticas do hospital para a vida da sociedade.

Nesta criação teatral, o hospital e suas características foram preservadas, objetivando afetar diretamente a percepção do público, a partir dos referenciais e implicações que cada espetador trazia consigo sobre aquele lugar, como o diretor esclarece: “a opção por um espaço não-convencional está essencialmente centrada numa interferência na percepção do espectador, e não numa pesquisa arquitetônica ou numa estética do espaço” (Araújo, 2002, p. 298). O resultado dessa escolha pode ser observado em algumas críticas de jornais da época:

Você pode desmaiar, ficar respingado de sangue ou passar mal com o cheiro de éter. Há também a possibilidade de uma crise de choro. Mas nenhum motivo é forte o bastante para deixar de percorrer os três andares do hospital atrás dos atores de O Livro de Jó (Fernando Oliva, Folha de São Paulo. São Paulo, 14 jun. 1995).

O ambiente hospitalar, com todo seu descalabro público e morbidez, está representado. O sangue que envolve Jó, em interpretação contagiante de Matheus Nachtergaele, o cheiro de éter, os corredores gélidos, as macas, o soro... Difícil manter a distância emocional em "O Livro de Jó". No sábado passado, um espectador desmaiou quando as cenas aconteciam ainda no primeiro andar. Provável mal-estar diante do corpo de Jó mergulhado na pia de sangue (Valmir Santos, Teatro Jornal. São Paulo, 18 fev. 1995).

Não há duvida de que o espetáculo tem pesado revestimento material. Atravessamos o equipamento hospitalar, sentimos o odor de um resquício de desinfetante e seguimos as pegadas sangrentas de Jó. Com isso, lembramos de um lugar onde se põe à prova a frágil carcaça humana (Mariângela Alves de Lima, O Estado de São Paulo. São Paulo, 17 fev. 1995).

As alusões dos críticos acerca dos imaginários que envolvem o local (hospital) revelam, nitidamente, a presença marcante que tiveram neste espetáculo, visto que o contexto daquele ambiente carrega consigo uma carga semântica considerável, que dialoga diretamente com fatores culturais, pessoais e coletivos, sociais e políticos. Identifica-se, assim, uma dialética do sujeito espectador com o lugar teatral significante, pois, ao aceitar participar do evento teatral dentro daquele ambiente poroso, não terá como deixar de considerar as questões que o 
espaço reverbera no seu imaginário, sensibilidade e senso estético.

Para além dos significados que a obra pudesse ter para cada espectador, as alusões ambientais igualmente constituíram os meios através dos quais a encenação de O Livro de Jó se estabeleceu, que longe de prezar por uma atmosfera interessante ou representar um símbolo, pretendia evidenciar o próprio espaço (material) através dos vínculos possíveis entre a realidade do hospital e as dramaticidades intrínsecas, capazes de serem exploradas na encenação, como bem esclarece Silvia Fernandes:

Este teatro de vivências e situações públicas não pretende, evidentemente, representar alguma coisa que não esteja ali. Ao contrário, a tentativa é de escapar do território específico da reprodução da realidade para tentar a anexação dela. É perceptível, nesse impulso de captura do real, o desejo dos criadores de levar o público a confrontarse com as coisas em estado bruto, seja por colocá-los num espaço concreto, contaminado de imaginário próprio, seja por misturar atores e não atores nas apresentações. (Fernandes, 2013, p. 85).

Expandindo um pouco mais a noção teatro de site-specific, Clifford Mclucas defende que esse gênero deve ser entendido a partir da coexistência e sobreposição de dois conjuntos básicos de arquitetura: a do lugar, que ele chamou de "anfitrião" (aquilo que é do local); e a da cena, que ele chamou de "fantasma" (aquilo que é temporariamente trazido ao local). Nesta acepção, o próprio local se torna um componente ativo na criação, que em vez de um espaço neutro de exposição ou cenário cênico para a ação dramática, se torna um agente da teatralidade. Em contrapartida, para se conformar como tal, é necessário que os elementos da linguagem teatral habitem este espaço, mesmo que temporariamente, para concretizar os fins estéticos pretendidos pelos agentes criativos.

Neste entendimento, o encontro entre as duas realidades, a do espetáculo (como suas necessidades estéticas) e a do espaço (com suas próprias maneiras de organização, dinâmicas e relações), elabora o universo da encenação, ao estabelecer um espaço ficcional no qual o caráter do real não pode ser apagado. Como bem ressalta o autor, o espaço no teatro site-specific "é um anfitrião que 
tem personalidade, história, caráter e narrativa nele descrito." (McLucas, 2001, apud Pearson, 2010, p. 11).

Esta compreensão pode se observada no espetáculo Hygiene (2005) do grupo XIX de Teatro, de São Paulo, que desenvolveu a encenação na Vila Operária Maria Zélia, construção do início do século XIX que fazia parte dos arredores das fábricas da Companhia Nacional de Tecidos, sendo desativada na década de 30, e, desde então, passou por várias mudanças estruturais, culminando como a deterioração ambiental e progressiva evasão dos moradores.

Inicialmente, a proposta do grupo teatral era realizar uma residência artística e extrair daquela vivência o material dramatúrgico (simbólico e biográfico) para a montagem do espetáculo em outro espaço. Porém, ao se aprofundar na memória do local, passou a dialogar com todas as circunstâncias daquele ambiente, e decidiu que ali seria o espaço ideal para a criação e apresentação do trabalho, porque a própria narrativa que ele proporcionava era a garantia de sua memória, como Renato Rebouças observa: "O passado abandonado da vila opera como um terreno arqueológico que, ao ser ocupado, explicita o transcorrer de sua memória fabril evidenciada nos lugares, nas formas e nas coisas." (Rebouças, 2010, p. 123).

Logo, a ocupação desse lugar determinou que a potencialidade narrativa do ambiente deveria ser o mote principal da encenação. Nesta estrutura, a linguagem teatral inserida naquele ambiente real ressuscitava, quase literalmente, os fantasmas adormecidos da Vila, que se materializavam na presença dos atores e se somavam com a presença de outros viventes que iam prestigiar a encenação naquele lugar, numa espécie de cortejo. Em uma análise da época, o crítico Valmir Santos descreve:

Fantasmas que habitam alguns prédios públicos abandonados há pelo menos três décadas na Vila Operária Maria Zélia (1917), no Belenzinho, zona leste, estão contracenando desde ontem com operários, imigrantes e lavadeiras - tal qual no início do século 19. (Santos, 2005, online).

Ao assumir uma quase reconstituição, com o teatro habitando o ambiente anfitrião, esse tipo de encenação revela que todos nós (atores, espectadores, cenógrafos, iluminadores, maquiadores, figurinistas, etc.) podemos ser 
interpretados como "convidados" do espaço, como Lehmann resume: "todos são estrangeiros no universo de uma fábrica, de uma central elétrica, de uma oficina de montagem" (Lehmann, 2011, p. 281), uma vez que a concretude do espaço se mantém após o evento cênico, devido as suas singularidades.

Compartilhando deste entendimento, Miwon Kwon (2002) observa que ser específica de um lugar não é o suficiente, é preciso qualificar como se dá esta relação de especificidade da obra. Para tanto, aponta três paradigmas que definem as especificidades comuns às práticas site-specific: o fenomenológico; o crítico social e o discursivo, que se interpenetram pela possibilidade de conceber o espaço como algo mais do que as características topográficas, antes, por toda malha que, em ressonância, rege esse espaço.

Em seu entendimento, o espaço fenomenológico estaria localizado no lugar literal concreto e significante da realidade (túnel, apartamento, garagem, hospital, etc.), que o teatro, fazendo uso como espaço cênico, estabelece as relações da experiência artística por ele desencadeada; o espaço crítico social inclui outra camada à ideia de espaço, pautando, especialmente, a criação do trabalho sob os vetores críticos e suas convenções engendradas naquele espaço em que os artistas passam a se endereçar no momento da instalação do trabalho, para além dos aspectos físicos do espaço, abordando questões sociais, econômicas e políticas dos lugares.

Já no espaço discursivo, o trabalho estaria descolado do lugar literal, passando a se ocupar de um assunto mais abrangente, um discurso que paira sob o espaço, seja ele ecológico, racial, de gênero ou outras formas identitárias relevantes a serem debatidas e suscitadas naquele espaço, como assegura Kwon (2002, p. 24):

As obras não querem mais ser um substantivo/ objeto, mas um verbo/processo, provocando a acuidade crítica (não somente física) do espectador no que concerne, inclusive, às condições ideológicas dessa experiência. O que significa que o local deve ser estruturado (inter) textualmente mais do que espacialmente, e podem ser estruturados para serem experimentados temporariamente, uma coisa depois da outra, e não como simultaneidade sincrônica. Essa transformação do espaço 
textualiza espaços e espacializa discursos. ${ }^{8}$

Nestes apontamentos, percebemos que as especificidades ressoantes do espaço acabam por gerar certa polissemia, e se compõem por meio dessas esferas de espaços que se afetam mutuamente e estabelecem um salto conceitual crucial na redefinição da experiência artística, subscrita pelos espaços imbricados nas obras.

Embora site-specific (literalmente traduzindo) se constitua através de duas palavras: site (espaço) e specific, derivada de specificity (especificidade), que vinculam a linguagem teatral ao que há de específico nos espaços selecionados para construir ali uma ficção, Fiona Wilkie (2004) explica que alguns criadores reivindicam aquilo que há de único no espaço, mais do que às especificidades (que podem ser comuns a vários locais), ao entender que, de certa forma, todo o trabalho teatral é, até certo ponto, específico do local, pois são concebidos tendo em vista um conjunto particular de espaços.

Por esse motivo, recorre ao adjetivo "exclusivo" para destacar as características únicas daquele espaço selecionado, sem o qual o trabalho artístico se esgota. De modo que, para fazer uma peça verdadeiramente site-specific, a autora entende que a obra tenha que estar totalmente vinculada ao seu espaço, tanto em seu conteúdo quanto na forma, quando o próprio espaço é um objeto da criação, caso contrário, se for móvel, o trabalho assumirá esse espaço como meio.

Refutando o maniqueísmo dessa afirmação, a própria autora observa que existem espetáculos que são totalmente site-specific - quando as camadas do espaço são reveladas através de referencias históricas, contextos sociais ou biográficos - e que, por outro lado, há outros espetáculos que fazem uso de um conceito espacial e utilizam espaço genérico ou espaços simpáticos aos

\footnotetext{
8 The "work" no longer seeks to be a noun/object but a verb/process, provoking the viewers' critical (not just physical) acuity regarding the ideological conditions of their view- ing. In this context, the guarantee of a specific relationship between an art work and its site is not based on a physical permanence of that relationship (as demanded by Serra, for example) but rather on the recognition of its unfixed impermanence, to be experienced as an unrepeatable and fleeting situation [...] this transformation of the site textualizes spaces and spatializes discourses. (Tradução nossa)
} 
propósitos da encenação. Portanto, há duas maneiras de lidar com essa questão:

\begin{abstract}
Alguns projetos são totalmente específicos do local, ou seja, eles não poderiam ocorrer em nenhum outro lugar sem perder o elo de significado e conexão; enquanto outros projetos mais flexíveis podem trabalhar em torno de um certo senso de lugar, isto é, uma atmosfera ou conceito no centro do projeto. (Wilkie, 2004, p. 53). ${ }^{9}$
\end{abstract}

Diante desta perspectiva, destaca que grande parte dos criadores desse gênero teatral assinala para uma sensação de esvaziamento, quando as peças são adaptadas para lugares similares ao original, mas, por outro lado, reconhecem que isso possibilita que o espetáculo possa circular por espaços afins (adaptados), desde que obedeça a lógica conceitual que anima a encenação. Na prática, isso significa que a concepção do espetáculo deve estar a par dos atravessamentos e interconexões possíveis.

Vejamos outro exemplo: em 2011 aconteceu uma encenação do texto Dois Perdidos Numa Noite Suja, de Plínio Marcos, dentro de uma casa localizada numa favela da cidade de Salvador (BA). Como concepção, entendia-se que aquele ambiente era fundamental para compreender as inter-relações plenas entre o contexto fenomenológico, sociopolítico e discursivo da encenação. Mas eis que, após uma premiação, o trabalho foi convidado a fazer apresentações na cidade de Évora, em Portugal, uma cidade interiorana do continente europeu, que, possivelmente, teria pouca ligação com o que os agentes criativos estavam tentando discutir na peça.

Após o convite ser aceito, se iniciou o processo de pensar nessa adaptação e verificou-se que, numa macroescala, o universo dos personagens, que migram do interior para a capital a fim de encontrar um futuro próspero, era similar ao dos refugiados do oriente médio (e africanos), que a cada dia migram dos seus países rumo a Europa, evadidos das guerras e fome. Diante dessa consciência, foi vislumbrado que o espaço onde eles poderiam viver nos países europeus, poderia,

Some projects are completely site-specific. they could not take place anywere alse without losing a string thread of meaning and connection; while other more flexible projects may work around a certain sense of place, the spirit or concept at the heart of the project would work in several- but not all- location. (Tradução nossa) 
facilmente, ser a garagem de carros em uma casa de classe média, alocação que provocaria uma reflexão sobre a exploração econômica e humana do capital, o grande conceito da peça.

Nessa adaptação espacial, fez falta a vizinhança, do barulho dos cachorros, dos becos e vielas por onde os espectadores brasileiros trafegavam para chegar à casa dos personagens, na versão original. Mas a adequação possibilitou abrir o trabalho a uma perspectiva humanitária, quando antes era enxergado apenas o viés socioeconômico, pelo contexto brasileiro vivido e para qual a encenação foi criada. Uma das camadas do trabalho foi perdida, mas outras se somaram. E, assim, intuímos que cada ocupação, travessia ou transgressão do espaço, oferece uma reinterpretação, uma reescrita, pois as adaptações seguem uma mesma intenção, que é buscar as mesmas sensações através da ativação do ambiente.

Consequentemente, podemos notar que o espaço, na poética site-specific, incorpora um conjunto de metáforas espaciais e culturais com as quais os artistas exploram uma variedade de espaços não-teatrais, compreendendo esses espaços como expandidos, devido as suas potencialidades. Assim, "a especificidade potencialmente restritiva do espaço, passa a permitir ambiguidade e multiplicidade." (Wilkie, 2004, p. 55).

Sendo assim, compreendemos que a encenação site-specific confia sua concepção, produção e recepção à complexa teia de convivência material entre o espaço, incluindo instalações, histórico e contexto. A esta materialidade, relativa à encenação, se opõe uma efemeridade inerente à linguagem teatral. Passada a temporada, o espaço retorna a sua condição anterior, à sua ocupação. Para o espectador que visitou o espetáculo, este espaço, mesmo que desativado, será portador de outros significados atinentes à encenação. Ele se transforma em matéria de memória para este espectador. 


\section{Considerações finais}

Por fim, sem a intenção de esgotar o assunto, entendemos que nesse conjunto de práticas artísticas, são as escolhas formais e estéticas que norteiam as encenações pelo conceito de site-specific. Essas escolhas decidem por um espaço que ao mesmo tempo tenha a possibilidade de interrogar e responder às intenções, tanto políticas quanto narrativas, do projeto de encenação. A adoção e a concepção desses espaços, como espaço cênicos, refletem as condições sociais nas quais os próprios criadores estão inseridos ou excluídos como cidadãos no interior de nossa sociedade.

Além disso, ressaltamos que o espaço, como força motriz da encenação, revela os próprios fundamentos e metodologias utilizados pelos agentes criativos. O espaço possibilita que diversas analogias sejam estabelecidas entre a encenação e os espectadores, que desfrutam dessa experiência munidos das suas próprias referências (imaginárias e identitárias). O mesmo lugar que acolhe o espectador intervém na própria dinamização do espaço, fator que implicará diretamente na leitura e percepção da obra inscrita num site-specific.

Se, no passado, a noção de espaço "alternativo" (partindo da arena) foi tida como uma reação dos artistas às condições de enunciação desde o palco frontal (drama burguês); hoje, a encenação em site-specific se constitui como uma experiência arrojada de linguagem teatral complexa, que rompe os pressupostos das convenções sociais a forma dramática. A encenação em site-specific não se traduz somente numa exibição, como puro exercício de linguagem teatral, ela convida os espectadores para uma experiência estética, ao mesmo tempo que não abandona os sentidos políticos do seu próprio trabalho teatral, cuja enunciação se inicia pela decisão acerca do próprio espaço. 


\section{Referências}

ARAÚJO, Antônio. Teatro da Vertigem: trilogia bíblica. São Paulo: Publifolha. 2002.

CALVET, Aldo; GONÇALVES, Lopes (org.). O Teatro de Arena como solução do problema da falta de teatros no Brasil. In: PRIMEIRO CONGRESSO BRASILEIRO DE TEATRO, 1953. Anais [...]. Rio de Janeiro: Gráfica Ouvidor, p.101-106.

CARREIRA, André. Teatro de invasión: la ciudad como dramaturgia. Córdoba: Documenta/Escenicas Ediciones, 2017.

COSTA, Iná Camargo. A hora do teatro épico no Brasil. São Paulo: Paz e Terra, 1996.

COSTA, Iná Camargo. Panorama do rio vermelho: ensaios sobre o teatro americano moderno. São Paulo: Nankin Editorial, 2001.

FERNANDES, Sílvia. Teatralidades contemporâneas. São Paulo: Perspectiva, 2013.

JONES, Margo. Theatre-in-the-Round. New York: McGraw-Hill Book Company, 1951.

KAYE, Nick. Site-Specific Art: performance, place and documentarion. Londres: Routledge, 2006.

KOSOVSKI, Lídia. A Morte de Danton na cidade escavada. O Percevejo online, Rio de Janeiro, v.1, n.1, 2009. Disponível em:

http://www.seer.unirio.br/index.php/opercevejoonline/article/view/483/408 .

Acesso em: 29 jun. 2020.

KWON, Miwon. One place after another: Site-specific art and locational identity. London: The MIT Press, 2002.

LEHMANN, Has Thies. Teatro Pós-drámatico. Tradução: Pedro Süssekind. Apresentação: Sérgio de Carvalho. 2. ed. São Paulo: Cosac Naify, 2011.

PAVIS, Patrice. Dicionário do teatro. Tradução de Jacó Guinsburg e Maria Lúcia Pereira. 3. ed. São Paulo: Perspectiva, 2007.

PEARSON, Mike. Site-specific performance. New York: Palgrave Macmillan. 2010.

REBOUÇAS, Ricardo Bolelli. A construção da espacialidade teatral: os processos de direção de arte do grupo XIX de teatro. 2010. 216 f. Dissertação (Mestrado em Artes Cênicas) - Centro de Artes da Universidade de São Paulo, São Paulo, 2010. 
SANTOS, Valmir. Trupe concebe "Hygiene" em vila operária. Teatrojornal. São Paulo, 13 de março de 2005. Disponível em:

https://teatrojornal.com.br/2005/03/trupe-concebe-qhygieneq-em-vila-operaria/. Acesso em: 29 jun. 2020.

SCHECHNER, Richard. Environmental theater. An expanded new edition including "Six Axioms For Environmental Theater". New York: Applause, 1994.

WILKIE, Fiona. Out of place: the Negotiation of Space in Site-Specific

Performance. 2004. 258 p. Tese (Doutorado em Filosofia) - University of Surrey, School of Arts, Guildford, 2004.

Recebido em: 30/06/2020

Aprovado em:03/08/2020 